\title{
Associations of Age and Pain With 9-Year Functional Health Trajectories
}

\section{The Moderating Role of Information-Processing Speed and Accommodative Coping}

\author{
Markus Wettstein ${ }^{1}$, Svenja M. Spuling ${ }^{1}$, Anja Cengia ${ }^{1}$, Sonja Nowossadeck ${ }^{1}$, \\ and Jonas Tesarz ${ }^{2}$ \\ ${ }^{1}$ German Centre of Gerontology, Berlin, Germany \\ ${ }^{2}$ Medical Hospital, Heidelberg University, Heidelberg, Germany
}

\begin{abstract}
We investigated whether information-processing speed and accommodative coping moderate associations of age and pain with 9-year functional health trajectories. Our sample consisted of 5,254 participants of the German Ageing Survey aged 40 years and older ( $M=62.33$ years) who participated in up to four measurement occasions. After controlling for sex, chronic diseases, and education, our longitudinal multilevel regression models revealed that the association of older age and higher pain severity with lower functional health was weaker in individuals with higher processing speed. The relationship between pain and functional health was weaker in individuals with higher scores on accommodative coping. Our findings suggest that processing speed and accommodative coping may be important compensatory resources buffering negative associations of age and pain with functional health.
\end{abstract}

Keywords: physical functioning, flexible goal adjustment, disablement process model, aging, longitudinal analysis

Functional health describes the extent to which an individual can independently execute everyday tasks (such as dressing, bathing, or climbing stairs). Good functional health is a major indicator of "successful aging" (Rowe \& Kahn, 1997) and is crucial for autonomy and quality of life (Schilling, Wahl, \& Reidick, 2013; Schöllgen, Morack, Infurna, Ram, \& Gerstorf, 2016). The World Health Organization (2015, p. 228) defines healthy aging as the "process of developing and maintaining the functional ability that enables well-being in old age," thus postulating a strong connection between functional health and well-being.

Functional health usually declines with advancing age (Baltes \& Smith, 2003; Berlau, Corrada, \& Kawas, 2009; Jacobs et al., 2012; Wettstein, Schilling, \& Wahl, 2016), which seems to result from an age-associated decrease in biological plasticity (Baltes, 1997) as well as from higher rates of chronic diseases and multimorbidity at older ages (Fuchs, Busch, Lange, \& Scheidt-Nave, 2012) compromising physical and functional health (Verbrugge \& Jette, 1994).

Besides chronological age, pain - particularly if chronic can be regarded as another major risk factor to impaired functional health and the onset of disability (Bryant, Grigsby, Swenson, Scarbro, \& Baxter, 2007; Eggermont et al., 2014; Jakobsson, Klevsgård, Westergren, \& Hallberg, 2003; Weiner, Rudy, Morrow, Slaboda, \& Lieber, 2006).

In contrast to age, by definition pain is a subjective experience. Experiencing pain in middle adulthood as well as in old and very old age is common (Bruckenthal, Reid, \& Reisner, 2009; Domenichiello \& Ramsden, 2019; Molton \& Terrill, 2014), with an age-related increase in pain prevalence (Jakobsson et al., 2003). Though pain might also be a consequence rather than a predictor of impaired functional health (e.g., Wettstein, Eich, Bieber, \& Tesarz, 2019), according to prior longitudinal research, it seems that the main pathway leads from pain to change in functional health (e.g., Bryant et al., 2007; Eggermont et al., 2014).

There are remarkable interindividual differences regarding intraindividual age-related trajectories of functional health (Leigh, Byles, \& Mishra, 2017; Wettstein et al., 2016; Willis, Jay, Diehl, \& Marsiske, 1992). These may be due to the role of certain person-specific and other resources (e.g., cognitive abilities, coping strategies), but 
also of risk factors (such as chronic diseases) as specified in theoretical frameworks such as the disablement process model (Verbrugge \& Jette, 1994) or the WHO's (2001) International Classification of Functioning, Disability and Health (ICF) model.

Similarly, individuals with pain represent a very heterogeneous group with regard to various psychological and biomedical characteristics (Cook \& Chastain, 2001; Hellström, Jansson, \& Carlsson, 2000; Jamison \& Brown, 1991; Jamison, Rudy, Penzien, \& Mosley, 1994; Loevinger, Shirtcliff, Muller, Alonso, \& Coe, 2012; Turk \& Rudy, 1988; Wettstein, Eich, Bieber, \& Tesarz, 2018). The extent to which pain compromises functional health varies considerably across individuals and depends on various individual characteristics, including age (Wettstein et al., 2019), as well as on psychosocial resources such as resilience (Wettstein et al., 2018) or coping strategies (Hall, Chipperfield, Heckhausen, \& Perry, 2010). Just like for age, there may thus be certain favorable person-specific characteristics and resources that could buffer the detrimental impact of pain on change in functional health.

\section{Accommodative Coping and Information- Processing Speed as Resources for the Maintaining Functional Health}

Little is known so far about these individual resources. According to theoretical frameworks such as the disablement process model (Verbrugge \& Jette, 1994) or the World Health Organization's ICF model (2001), intraindividual factors (or "personal factors" according to the ICF model) affect the risk of functional limitations or activity restrictions. Specifically, the disablement process model postulates that there is a main pathway leading from pathology and impairments to functional limitations and disability. This pathway can be influenced by extraindividual factors (e.g., external supports), intraindividual factors (e.g., coping), and risk factors (e.g., demographic variables), which either augment or reduce the impact of impairments on disability. In this study, we modify these model assumptions by considering such intraindividual and risk factors as well as their interactions as direct predictors of functional health.

Among the intraindividual factors specified in the disablement process model, and among the personal factors specified in the ICF model, cognitive abilities and coping strategies could be of primary importance. Cognitive abilities, particularly information-processing speed, a key marker of cognitive functioning (Finkel, Reynolds, McArdle, \& Pedersen, 2007; Heikkinen, 2011; Lindenberger, Mayr, \& Kliegl, 1993; Salthouse, 1996), are crucial prerequisites for functional health (Atkinson et al.,
2009; Desjardins-Crépeau et al., 2014; Willis et al., 1992). An age-related decline in cognitive functioning - again including processing speed (Finkel, Ernsth-Bravell, \& Pedersen, 2016; Wahl, Schmitt, Danner, \& Coppin, 2010) - is accompanied by a decline in indicators of functional health (Finkel et al., 2016; Praetorius Björk, Johansson, \& Hassing, 2016; Royall, Palmer, Chiodo, \& Polk, 2004; Wahl et al., 2010).

Moreover, with reference to coping, when individuals get older and their resources from different domains (e.g., sensory and cognitive functioning) decrease, coping strategies may gain in importance in order to foster resilience (Leipold \& Greve, 2009), to achieve certain goals, and to prevent functional health decline. Specifically, according to the dual-process model of assimilative and accommodative coping (Brandtstädter, 2015; Brandtstädter \& Rothermund, 2002), strategies of accommodative coping aim at adapting to constraints by disengaging from goals, positive reappraisal of loss, and by adjusting expectations and standards. With increasing age, individuals show higher investment in strategies of accommodative coping (Brandtstädter \& Greve, 1994; Brandtstädter, Rothermund, Kranz, \& Kühn, 2010; Rothermund \& Brandstädter, 2003). Moreover, accommodative goal management strategies in later life have been found to be associated with better physical and functional health (Arends, Bode, Taal, \& Van de Laar, 2018; Hall et al., 2010; Kelly, Wood, \& Mansell, 2013).

\section{Do Accommodative Coping and Information-Processing Speed Moderate Associations of Age and Pain With Functional Health?}

Information-processing speed and accommodative coping may not only represent resources or protective factors for functional health, they may also be moderators of the pathways leading from the risk factors age and pain to functional health and changes in functional health. Specifically, they might be compensatory resources that buffer the negative impact of age and pain on functional health levels and changes. This is in line with the disablement process model (Verbrugge \& Jette, 1994), which postulates that the "main pathway" leading from pathology and impairments including pain and chronic diseases as factors driving functional decline and disability (e.g., Bryant et al., 2007; Eggermont et al., 2014) - to functional limitations is modified by various moderating variables that may either act as risk factors or as protective factors.

Thus, there may be a meaningful interaction between pain and processing speed: Previous research showed that individuals with pain who are additionally affected by impaired cognitive abilities are particularly restricted 
regarding health and mobility (Schepker et al., 2016). This in turn might mean that cognitive abilities, including speed as a crucial cognitive ability marker, function as a compensatory resource that gains in importance to maintain functional health when pain sets in or worsens. A similar compensatory role of cognitive resources was reported with regard to health conditions other than pain, for example, for older adults with sensory impairments (Heyl \& Wahl, 2012) or in oldest-old individuals who are physically frail (Dupuy, N'Kaoua, Dehail, \& Sauzéon, 2019).

Moreover, given that (very) old age represents a particularly vulnerable life phase with accumulated risk of diseases (Heikkinen, 2011) and high risk of resource losses, including decline in functional health (Baltes \& Smith, 2003), information-processing speed may also become more important as a compensatory resource for maintaining functional health at older ages. Specifically, individuals restricted in their mobility either because of pain or complaints related to older age may particularly benefit from intact information-processing speed resources with regard to their functional health and independence in everyday life. For instance, certain adaptation strategies and mechanisms may help to maintain functional health despite pain or advanced age. These strategies - including accommodative coping- may to some extent all be cognitively demanding, thus requiring "mental complexity" (Leipold \& Greve, 2009, p. 46) and intact cognitive resources, including processing speed.

With regard to coping, particularly those strategies targeting accommodative coping have been found to facilitate adjustment to pain or to other health conditions (van Lankveld, van Diemen, \& van Nes, 2011), such as sensory impairment (Boerner \& Wang, 2012; Brennan-Ing, Boerner, Horowitz, \& Reinhardt, 2013; Heyl, Wahl, \& Mollenkopf, 2007; Wettstein, Wahl, \& Heyl, 2019). Specifically, accommodative coping was found to be associated with lower depression scores in chronic pain patients, particularly in those experiencing high-intensity pain (Schmitz, Saile, \& Nilges, 1996). Regarding physical health outcomes, Hall et al. (2010) report that, for individuals with chronic conditions (including pain-eliciting diseases such as arthritis), more goal disengagement - an accommodative coping strategy - was associated with better physical health after 5 years. In contrast, individuals with pain who do not adjust goals and who do not engage in other accommodative coping strategies might end up in an "escalation of commitment" and an "exhaustion of resources" (Brandtstädter \& Rothermund, 2002), so that these exploited resources cannot be invested in maintaining functional health.

In addition, associations of accommodative coping with functional health might be age-differential. Because of age-related loss of resources, accommodative coping might get particularly important for health (Hall et al., 2010) and well-being with advancing age (Loidl \& Leipold, 2019; Rothermund \& Brandstädter, 2003) as certain goals are no longer attainable because of this altered resource situation. As an example, Hall et al. (2010) found that higher goal disengagement was associated with better subsequent physical health in old-old, but not in young-old individuals.

\section{Research Questions and Expectations}

In this study, we investigate how age, pain, informationprocessing speed, and accommodative coping as well as their interactions are longitudinally associated with 9-year changes in functional health in the second half of life.

Our expectations, also illustrated in Figure 1, are as follows:

1. Older age and the experience of pain are associated with lower functional health and with steeper longitudinal decline in functional health, whereas higher information-processing speed and higher engagement in accommodative coping are associated with better functional health and less steep decline in functional health. With regard to within-person, time-varying associations, we analogously expect that, on occasions when individuals experience higher pain severity and score lower on information-processing speed, they also report poorer functional health.

2. Because of compensatory processes, there may be meaningful interactions of information-processing speed and accommodative coping with age and pain: Associations of accommodative coping and information-processing speed with functional health and with changes in functional health are expected to be closer under "high-vulnerability" conditions, i.e., at older ages as well as in individuals whose pain is more severe. We thus expect that information-processing speed and accommodative coping are more closely associated with functional health and changes thereof in older individuals and in individuals experiencing overall higher pain severity. Additionally, with regard to within-person associations, our assumption is that, on occasions when individuals report higher pain severity, their information-processing speed performance and accommodative coping scores are more closely related with functional health than on measurement occasions with lower pain severity.

\section{Methods}

\section{Study Population and Sample Description}

We used data from the German Ageing Survey, a cohortsequential study comprising German community-dwelling 


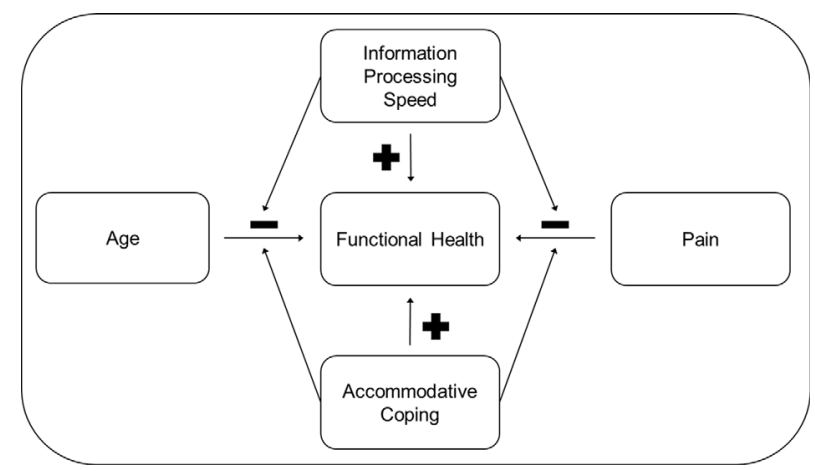

Figure 1. Assumed relations of age, pain, information-processing speed, and accommodative coping with functional health: Direct and moderated associations.

adults aged 40 years and older (Klaus et al., 2017). Six measurement waves (T1: 1996, T2: 2002, T3: 2008, T4: 2011, T5: 2014; T6: 2017) have been completed so far. Based on national probability sampling, a new baseline sample was drawn every 6 years $(1996,2002,2008$, and 2014). Baseline samples were systematically stratified by age, sex, and region (former West or East Germany). If study participants agreed, they were reinterviewed on the subsequent measurement occasions. In 2011 and in 2017, only participants from previous baseline samples were reassessed, but no new baseline samples were drawn.

Ethical approval was not obtained as this is not mandatory for general surveys in Germany. The German Ageing Survey was approved and funded by the German Federal Ministry for Family Affairs, Senior Citizens, Women, and Youth. Personal interviews were held by trained interviewers based on a standardized questionnaire. In addition, respondents were given a self-administered questionnaire. Informed consent after the initial survey participation of each study participant is mandatory for future survey participation. The German Ageing Survey does not employ invasive methods. This survey maintains an academic advisory board which ensures the scientific quality of the survey.

For our analyses, we use all measurement waves from 2008 onward because pain had not been assessed on the measurements before 2008. Our study sample consists of 5,254 individuals who had provided valid information on their functional health (and on all other variables we included as predictors) in 2008 and/or at one or several of the follow-up measurement occasions (2011, 2014, 2017). A sample description is shown in Table 1.

\section{Measures}

\section{Functional Health}

Functional health was assessed on each measurement occasion $(2008,2011,2014,2017)$ by the physical functioning subscale of the 36-Item Short Form Health Survey (SF-36;
Table 1. Sample description

\begin{tabular}{ll}
\hline Variable & $M \pm S D$ or $n(\%)$ \\
\hline Age (baseline), $M \pm S D$ & $62.33 \pm 11.48$ \\
Age groups (baseline): & \\
$\quad 40-60$ years $(M=51.53$ years, & $2,362(45 \%)$ \\
$S D=5.63$ years), $n$ (\%) & \\
$>60$ years ( $M=71.15$ years, & $2,892(55 \%)$ \\
$\quad S D=6.38$ years), $n$ (\%) & \\
Female sex, $n(\%)$ & $2,584(49.2 \%)$ \\
Education: & \\
$\quad$ Low $n$ (\%) & $457(8.7 \%)$ \\
$\quad$ Medium $n$ (\%) & $2,811(53.5 \%)$ \\
$\quad$ Elevated $n$ (\%) & $680(12.9 \%)$ \\
$\quad$ High $n$ (\%) & $1,306(24.9 \%)$ \\
Functional health ${ }^{1}$ (baseline, $\left.0-100\right), M \pm S D$ & $85.20 \pm 21.03$ \\
Pain ${ }^{2}$ (baseline), $M \pm S D$ & $2.30 \pm 1.57$ \\
Information-processing speed (baseline), $M \pm S D$ & $43.04 \pm 14.11$ \\
Accommodative coping (baseline), $M \pm S D$ & $3.58 \pm 0.56$ \\
Number of chronic conditions (baseline), $M \pm S D$ & $2.27 \pm 1.81$ \\
Number of observations, $M \pm S D$ & $2.67 \pm 1.25$ \\
\hline Note $M=$ m
\end{tabular}

Note. $M=$ mean, $S D=$ standard deviation. ${ }^{1}$ Higher values indicate better functional health. ${ }^{2}$ Higher values indicate higher pain intensity.

Bullinger \& Kirchberger, 1998). Study participants reported their degree of limitation (limited a lot, limited a little, or not limited at all) with regard to 10 typical everyday activities (e.g., walking several blocks). The answers were summed and transformed according to the manual guidelines (Bullinger \& Kirchberger, 1998), resulting in a sum score ranging from 0 to 100, with higher scores indicating better functional health.

\section{Age}

To investigate the role of chronological age for functional health levels and changes, we included individuals' baseline age (in years).

\section{Pain}

Pain intensity was assessed by a single-item question ("Have you had persistent or recurrent pain during the last four weeks?") on each measurement occasion. Answers ranged from $1=$ no pain to $6=$ very severe pain .

\section{Information-Processing Speed}

Assessment of information-processing speed, which was measured on each measurement occasion, was based on the established and frequently used Digit Symbol Substitution Test, which is part of the Wechsler Adult Intelligence Scale (WAIS-R; Tewes, 1991).

\section{Accommodative Coping}

A 10-item short form of the original flexible goal adjustment scale (Brandtstädter \& Renner, 1990), which has also been 
used in other studies (e.g., Freund \& Baltes, 2002), was used to assess baseline accommodative coping. This short-form was developed by removing 5 items from the 15 -item original scale. The criterion for item removal was that omitting the respective item led to an increase in internal consistency (Cronbach's $\alpha$ ) of the scale. Items (e.g., "I usually find something positive even in giving up something I cherish") were answered on a 5-point Likert scale ranging from 1 (not at all true) to 5 (totally true) and were aggregated to a sum score, with higher values indicating higher endorsement of accommodative coping. Unlike pain and information-processing speed, accommodative coping could not be specified as a time-varying predictor, because it was assessed only in 2008 and 2011. It was therefore included as a time-invariant predictor assessed at baseline (i.e., in 2008; Cronbach's $\alpha=.82$ in this study).

\section{Control Variables}

We also included study participants' sex, number of chronic diseases (as time-varying control variable), and education in the analyses, because these factors are important additional predictors of functional health levels and changes (Verbrugge \& Jette, 1994; World Health Organization, 2001). Moreover, they might be confounding factors, for example, with regard to associations of age, pain, or information-processing speed with functional health. The assessment of education was based on the International Standard Classification of Education coding (UNESCO, 2012). Based on school and professional education, this coding differentiates between four educational groups, namely, individuals with low, medium, elevated, and high education. As an indicator of multimorbidity, number of chronic diseases was assessed on each measurement occasion based on a disease list: Participants indicated which of 11 chronic conditions (such as diabetes, cancer, or cardiovascular diseases) they had.

\section{Statistical Analyses}

We ran longitudinal multilevel regression models (Hox \& Kreft, 1994; Ram \& Grimm, 2015) using Stata 15.0 (StataCorp., 2017) to investigate how age, pain, information-processing speed, and accommodative coping are related to functional health as well as to changes in functional health. "Time in study" (in years; beginning in 2008) was specified as time metric. Pain, information-processing speed, and number of chronic diseases were specified as time-varying predictors. In order to disentangle between-person vs. within-person effects of the time-varying predictors, our modeling approach followed common recommendations (Hoffman \& Stawski, 2009; Schwartz \& Stone, 1998): Specifically, the person-specific mean score of each individual across all their available measurement occasions was computed for each time-varying predictor, which corresponds to the between-person predictor effect. The measurement-occasion specific deviations from this mean score were additionally computed and included, corresponding to the within-person, time-varying predictor effects.

Age and information-processing speed were grandmean-centered to facilitate the interpretation of the intercept and the other effects. For the same purpose, we recoded pain $(0=$ no pain to $5=$ very severe pain $)$ and accommodative coping (0-4; higher scores indicate higher endorsement of accommodative coping).

\section{Results}

\section{Trajectory of Functional Health}

First, we specified a linear change model and a quadratic change model without additional predictors to investigate the general shape of 9-year change in functional health. The model including a quadratic time component to describe functional health trajectories did not provide a better model fit than the respective linear change model in terms of the BIC difference (Kass \& Raftery, 1995; the difference $2[\Delta \mathrm{BIC}]$ was $<6$ ). Also, the likelihood ratio test did not reach statistical significance, thus indicating no goodness-of-fit difference between models. Therefore, the more parsimonious linear change model was chosen, indicating a mean-level trend of gradual linear decline in functional health over 9 years (see Figure 2). As can be seen from Figure 2, there was also remarkable interindividual heterogeneity with regard to functional health levels and changes.

For illustrative purposes only, mean-level trajectories of two different specific age groups are shown in Figure 2 (as well as in some of the following figures), namely, of those persons aged 40 to 60 years at baseline and those persons who were older than 60 years at baseline. In the following results of our multilevel regression analyses (see next section), age was treated as a continuous, metrical predictor and was not categorized in age groups.

\section{Predictors of Functional Health}

In the extended model with additional predictors (see Table 2), baseline functional health was poorer in individuals who were older, who reported higher overall pain, and who scored lower on overall information-processing speed (both averaged across all available measurement occasions, thus corresponding to between-person effects). Accommodative coping was not significantly associated with baseline functional health. 


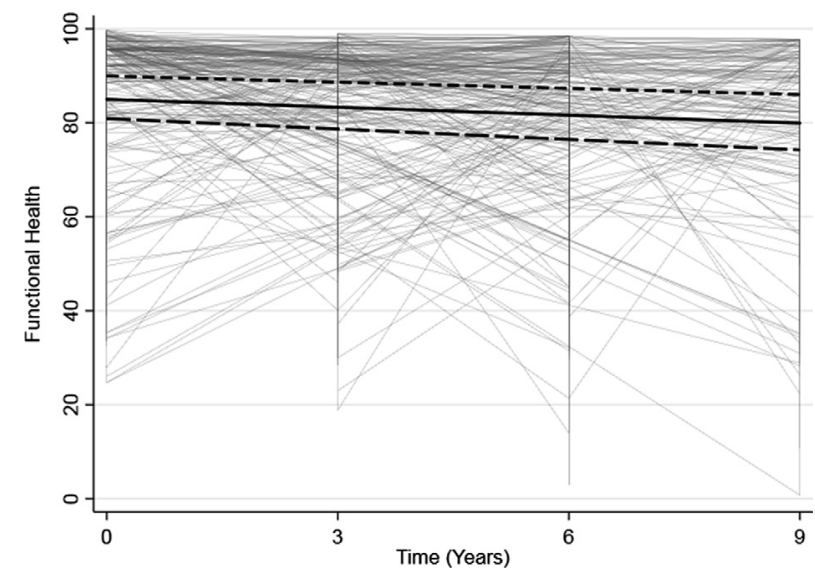

Figure 2. Trajectories of functional health over 9 years. Note. The thick black line corresponds to the mean-level trajectory of the total sample. The upper dashed black line represents the mean-level trajectory of individuals aged 40 to 60 years at baseline. The lower dashed line is the mean level trajectory of individuals older than 60 years at baseline. The thin gray lines correspond to individual trajectories (random selection of 1,000 study participants).

With regard to the time-varying, within-person effects, individuals reported better functional health on measurement occasions when they reported less pain severity and scored higher on information-processing speed. Finally, regarding predictors of change in functional health, information-processing speed reached statistical significance: Individuals with overall higher scores on information-processing speed, considered across all available measurement occasions (between-person effect), revealed a less steep 9-year decline in functional health.

\section{Interactions between Predictors of Functional Health}

However, the described effects need further specification because, as expected, several interactions of informationprocessing speed and accommodative coping with age and pain were significant: Regarding between-person effects, the association of overall higher informationprocessing speed with better functional health at baseline was stronger in individuals who were older at baseline as well as in individuals with overall higher pain severity levels (see Figure 3). Also, the association of higher accommodative coping scores with better baseline functional health was closer in individuals with overall higher pain severity (see Figure 4). As can be seen in Figure 3, age also moderated the association of information-processing speed with change in functional health: overall higher informationprocessing speed was associated with less steep functional health decline particularly in older individuals. In addition, pain interacted with age regarding its associations with baseline functional health and with functional health
Table 2. Predictors of change in functional health

\begin{tabular}{|c|c|}
\hline & $\begin{array}{l}\text { Fixed regression } \\
\text { coefficients }[S E]\end{array}$ \\
\hline \multicolumn{2}{|l|}{ Fixed effects } \\
\hline Intercept & $97.23 * * *[1.71]$ \\
\hline Time & $-0.24[0.36]$ \\
\hline \multicolumn{2}{|l|}{ Predictors of intercept (between-person) } \\
\hline $\operatorname{Sex}^{1}$ & $-2.59 * * *[0.48]$ \\
\hline Education & $1.48 * * *[0.25]$ \\
\hline Number of diseases & $-2.34 * * \star[0.16]$ \\
\hline Age & $-0.39 * * *[0.10]$ \\
\hline Pain & $-8.25 * * *[0.77]$ \\
\hline Information-processing speed & $0.07 *[0.03]$ \\
\hline Accommodative coping & $0.38[0.60]$ \\
\hline Age $\times$ Pain & $-0.05 *[0.02]$ \\
\hline Age $\times$ Information-processing speed & $0.01 * * *[0.00]$ \\
\hline Age $\times$ Accommodative coping & $0.06[0.04]$ \\
\hline Pain $\times$ Information-processing speed & $0.07 * * *[0.02]$ \\
\hline Pain $\times$ Accommodative coping & $1.19 * * *[0.29]$ \\
\hline \multicolumn{2}{|l|}{ Within-person predictors } \\
\hline Number of diseases & $-0.67 * \star \star[0.13]$ \\
\hline Pain & $-1.92 * *[0.59]$ \\
\hline Information-processing speed & $0.05^{\star \star}[0.02]$ \\
\hline Age $\times$ Pain & $-0.01[0.01]$ \\
\hline Age $\times$ Information-processing speed & $0.01 * *[0.00]$ \\
\hline Pain $\times$ Information-processing speed & $0.03[0.02]$ \\
\hline Pain $\times$ Accommodative coping & $-0.19[0.22]$ \\
\hline \multicolumn{2}{|l|}{ Predictors of slope (between-person) } \\
\hline Sex $\times$ Time & $-0.01[0.09]$ \\
\hline Education $\times$ Time & $0.04[0.05]$ \\
\hline Number of Diseases $\times$ Time & $-0.14 * \star *[0.03]$ \\
\hline Age $\times$ Time & $0.00[0.02]$ \\
\hline Pain $\times$ Time & $0.11[0.17]$ \\
\hline Information-processing speed $\times$ Time & $0.03 * * *[0.01]$ \\
\hline Accommodative coping $\times$ Time & $-0.03[0.13]$ \\
\hline Age $\times$ Pain $\times$ Time & $-0.01 * * \star[0.00]$ \\
\hline Age $\times$ Information-processing speed $\times$ Time & $0.00 * * *[0.00]$ \\
\hline Age $\times$ Accommodative coping $\times$ Time & $-0.00[0.01]$ \\
\hline Pain $\times$ Information-processing speed $\times$ Time & $-0.00[0.00]$ \\
\hline Pain $\times$ Accommodative coping $\times$ Time & $-0.08[0.07]$ \\
\hline \multicolumn{2}{|l|}{ Random effects } \\
\hline Variance slope & $1.88 * * *[0.17]$ \\
\hline Variance intercept & $165.66 * * *[5.91]$ \\
\hline Covariance intercept $\times$ Slope & $-1.25[0.85]$ \\
\hline Residual variance & $109.71 * * *[2.67]$ \\
\hline
\end{tabular}

Note. ${ }^{*} p<.05,{ }^{* \star} p<.01,{ }^{* \star *} p<.001 .{ }^{1} 0=$ male, $1=$ female.

changes: In older individuals, higher overall levels of pain severity were more strongly associated with lower functional health and with steeper functional health decline than in younger individuals.

With regard to within-person associations, the positive measurement-occasion specific association of 


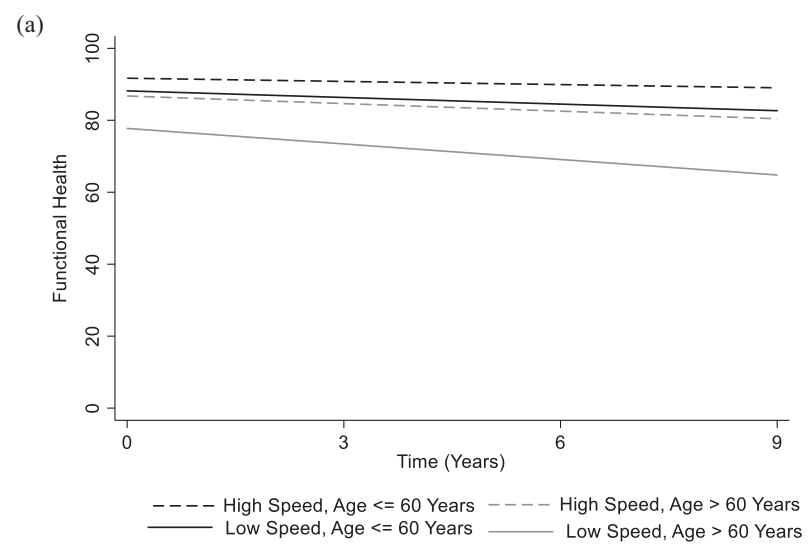

(b)

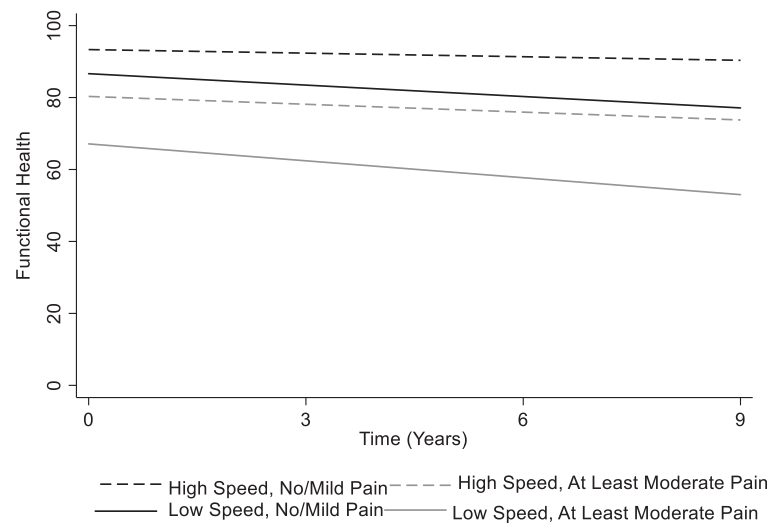

Figure 3. (a) Association of information-processing speed with functional health by age. (b) Association of information-processing speed with functional health by pain. Note. Speed $=$ information-processing speed (Digit Symbol Substitution test).

information-processing speed with functional health was also stronger in older compared to younger individuals. ${ }^{1}$

\section{Discussion}

In this study, we investigated the role of age, pain, information-processing speed, and accommodative coping strategies for functional health and for 9-year trajectories of functional health in adults aged 40 years and older. We also analyzed interactions between these risk and protective factors. Our main findings were as follows: In the total sample, overall more severe pain, overall lower information-processing speed, and older age were associated with

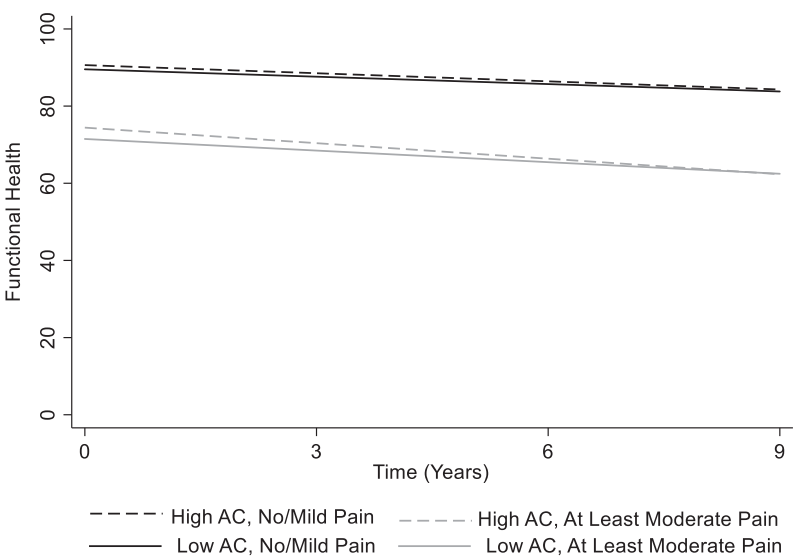

Figure 4. Association of accommodative coping with functional health by pain. Note. $\mathrm{AC}=$ accommodative coping.

poorer functional health. These associations of pain and information-processing speed with functional health became stronger with advancing age. Also, informationprocessing speed and accommodative coping were more closely associated with functional health for individuals who reported more severe pain. From a within-person perspective, information-processing speed and pain were also significantly associated with functional health: On occasions when individuals reported more pain and scored lower on information-processing speed, they also reported poorer functional health. For information-processing speed, this association was again stronger in older individuals. Finally, information-processing speed was also associated with a long-term decline in functional health, with individuals who had overall better information-processing speed scores revealing less decline in functional health over time. Again, this effect was stronger among older individuals. Only one effect was limited to older adults, namely, the association between overall more severe pain and steeper functional health decline.

\section{Functional Health in the Second Half of Life: The Role of Age, Pain, Information-Processing Speed and Accommodative Coping}

Based on longitudinal analyses (controlling for education, sex, and number of chronic diseases), older age and the

\footnotetext{
${ }^{1}$ Because associations of the interactions between pain and speed as well as between pain and accommodative coping with functional health, both considered from a between-person and within-person perspective, might vary as a function of age, we computed additional exploratory analyses by including also terms of higher-order interactions (age $\times$ pain $\times$ speed, age $\times$ pain $\times$ accommodative coping) on functional health and on change in functional health. Of these six additional interactions, five were not significant, suggesting that most interactions of pain with information-processing speed and with accommodative coping are not age-differential. Only the interaction of age with pain (within-person) and accommodative coping reached statistical significance, indicating that only in older individuals was there a trend of small effect size toward stronger time-varying associations between pain and functional health in those with higher accommodative coping scores.
} 
experience of more severe pain were, as expected, identified as risk factors that are significantly associated with lower functional health. Also, when considered longitudinally from a within-person, time-varying perspective, on measurement occasions when individuals reported more severe pain, their functional health was more impaired. This finding is in line with the predictions from the disablement process model (Verbrugge \& Jette, 1994), and it corresponds to results of other empirical studies that investigated the role of chronological age (Berlau et al., 2009; Jacobs et al., 2012; Wettstein et al., 2016) and pain (Bryant et al., 2007; Eggermont et al., 2014; Jakobsson et al., 2003; Weiner et al., 2006) for functional health.

In contrast, and also in line with our expectations, higher information-processing speed can be seen as a protective factor that - both from a within-person and a betweenperson perspective-was significantly associated with better functional health and less 9-year decline in functional health. These findings correspond with prior research (and again with the assumptions of the disablement process model; Verbrugge \& Jette, 1994) regarding the role of cognitive abilities, and particularly of information-processing speed, for health and disablement (Finkel et al., 2016; Praetorius Björk et al., 2016; Royall et al., 2004; Wahl et al., 2010). However, we have to acknowledge that the time-varying association between information-processing speed and functional health observed in this study should be carefully interpreted with regard to causality: Motor and functional health changes might precede cognitive, speed-of-processing related changes (Finkel et al., 2016). There might also be a reciprocal association, with higher information-processing speed leading to better functional health and vice versa.

Unexpectedly, accommodative coping was not significantly associated with levels and changes in functional health, though other studies have reported a meaningful association (Arends et al., 2018; Hall et al., 2010; Kelly et al., 2013). It was not possible to model accommodative coping as a time-varying predictor in this study as it was not assessed at every measurement occasion. However, change in accommodative coping might actually be related to functional health changes, rather than accommodative coping assessed at one point in time. Moreover, strategies of accommodative coping might be an important determinant of other key outcomes beyond functional health, such as well-being (Heyl et al., 2007; Schmitz et al., 1996; Wahl, Becker, Schilling, Burmedi, \& Himmelsbach, 2005; Wettstein et al., 2019). The most beneficial effects of coping may not be achieved by accommodative coping alone, but rather by a broader coping repertoire including accommodative, assimilative and other strategies (Bailly et al., 2016; Heyl et al., 2007; Kelly et al., 2013; Wettstein et al., 2019). Finally, even though the main effects of accommodative coping considered as a single predictor were not significant, there was one significant interaction effect including accommodative coping. This coping mode thus seems to be a moderator of associations between functional health and its determinants rather than a predictor on its own.

\section{Information-Processing Speed and Accommodative Coping as Moderators of Associations Between Age, Pain, and Functional Health}

Generally, changes in major developmental domains such as functional health are not driven solely by single factors, but rather by "multi-indicator constellations" (Brandmaier, Ram, Wagner, \& Gerstorf, 2017), including interactions between these factors. Indeed, we found empirical support for our assumption that information-processing speed and accommodative coping were more closely positively associated in individuals who revealed "higher vulnerability," either in terms of older age or of experiencing more severe levels of pain. These moderation effects can also be interpreted differently: As long as other resources (i.e., processing speed, accommodative coping) are sufficiently available, the negative association of age and pain with functional health is buffered. Overall higher levels of information-processing speed were more strongly associated with better baseline functional health in older than in younger individuals and in adults with overall higher levels of pain severity compared to those experiencing less severe or no pain. This, in turn, also means that individuals who experience the "double burden" of impaired cognitive resources in terms of lower information-processing speed and more severe pain report particularly poor functional health, which is in line with other findings (Schepker et al., 2016). Similarly, in individuals who reported overall higher pain severity, accommodative coping was more strongly positively associated with baseline functional health than in individuals with less severe pain. Individuals with pain might thus particularly benefit from accommodative coping with regard to their functional health. Accommodative coping might help these individuals to give up unattainable goals, thus preventing them from "escalation of commitment" and "exhaustion of resources" (Brandtstädter \& Rothermund, 2002), which might further impair their vulnerable functional health status.

Some of these interactions were also significant when considered longitudinally: In older individuals, the occasion-specific, within-person association of processing speed with functional health was stronger than in younger individuals. That is, particularly for older adults, scoring higher on information-processing speed at a specific 
measurement occasion was associated with better functional health at this occasion. Finally, the association of overall higher information-processing speed with less steep 9-year decline in functional health was also moderated by age, with stronger associations in older compared to younger individuals.

Some of our assumptions were not met. Specifically, we did not find evidence for a stronger association between accommodative coping and functional health with advancing age, though the respective interaction effect was marginally significant $(p=.069)$. Again, it might be the availability of a broad coping repertoire rather than of a single strategy that buffers the negative effect of age on functional health. Moreover, also unexpectedly, the effect of occasion-specific deviations in pain on functional health were not buffered by information-processing speed or accommodative coping. One possible explanation is that reacting to such a - potentially temporary - increase in pain may take time, so that accommodative coping efforts might be augmented from then on, resulting in a "lagged effect" with less compromised health occurring not at once, but at a subsequent measurement occasion. Finally, when controlling for the within-person effect of pain, there was no significant interaction of these overall pain severity levels with information-processing speed or accommodative coping regarding change in functional health. Individuals who experience less pain thus report better functional health than those with more severe pain, and this difference does not increase over time, but rather remains stable.

The findings of this study have several implications for future practice. From a medical perspective, the current guidelines for improving functioning in pain patients is primarily focused on pain control and on training the musculoskeletal system. However, intrapersonal resources, including cognitive abilities such as information-processing speed and (accommodative) coping strategies, have seldom been taken into account so far as potential components of multimodal interventions, though cognitive abilities as well as the use of adaptive coping strategies, can be regarded as modifiable protective factors (Arends et al., 2018; Rebok et al., 2014; Schmiedek, Lövdén, \& Lindenberger, 2010; Wettstein \& Wahl, 2017). Patients suffering from pain have already been found to benefit from a goal-management intervention with regard to their experience of positive affect (Arends et al., 2018), and such beneficial effects might be also achieved for functional health. Also, cognitive-behavioral therapy approaches seem to be beneficial for pain patients (Ehde, Dillworth, \& Turner, 2014) and might be an adequate format for teaching and practicing coping techniques (Kashikar-Zuck et al., 2013; Turner, Holtzman, \& Mancl, 2007). According to the WHO's (2015) public-health framework for healthy aging, the environment may contribute to an individual's healthy aging by promoting "capacity-enhancing behaviors." Accommodative as well as other coping techniques may be such behaviors. However, we acknowledge that more evidence is first needed in support of the assumed causal pathways leading from cognitive abilities, accommodative coping, and pain to functional health before deriving potential interventions.

\section{Strengths and Limitations}

Among the strengths of this study are its population-based, representative sample and the large sample size. Moreover, the 9-year longitudinal observation period enabled us to model long-term changes in functional health in a representative, nonclinical sample of individuals aged 40 years and older. Additionally, information-processing speed, pain, and the number of chronic diseases were assessed on every measurement occasion so that their role as time-varying predictors could be investigated.

However, there are also several limitations. Only one coping strategy was assessed, but, as already stated, the use of a broad coping repertoire including different strategies might be most beneficial for health outcomes (Bailly et al., 2016; Haynes, Heckhausen, Chipperfield, Perry, \& Newall, 2009; Kelly et al., 2013; Siltanen et al., 2018; van Diemen, van Nes, Geertzen, \& Post, 2018). Unfortunately, other coping strategies such as assimilative coping as the "antagonist" of accommodative coping (Brandtstädter \& Greve, 1994) were not available in this study.

Similarly, only one cognitive function was assessed in this study, namely, information-processing speed. This cognitive component seems to be of particular relevance for functional health (Atkinson et al., 2009; DesjardinsCrépeau et al., 2014; Finkel et al., 2016; Wahl et al., 2010; Willis et al., 1992), but there may be additional cognitive functions that are meaningfully associated with functional health trajectories.

Generally, there might also additional psychosocial and other factors, such as subjective age (Levy, Slade, \& Kasl, 2002; Sargent-Cox, Anstey, \& Luszcz, 2012), that drive changes in functional health. Subjective age, or selfperceptions of aging, might also act as a moderating or mediating factor regarding the impact of different risk and protective factors on outcomes of health (e.g., Moor, Zimprich, Schmitt, \& Kliegel, 2006), which deserves further investigation.

Moreover, brief measures of study variables were used in this study in order to reduce participants' time burden and to increase their willingness to participate. Therefore, pain was assessed by a single-item question on each measurement occasion. The exact pain location as well as the extent 
to which pain impairs daily activities (i.e., pain interference) were not assessed, though they might be even more strongly associated with outcomes of functional health than mere pain severity (Eggermont et al., 2014). However, the degree to which pain impairs activities of daily living might to some extent have been measured by our outcome measure of functional health, though an impaired functional health is, of course, not necessarily solely due to pain.

Also, we did not measure pain chronicity. However, acute pain may require other specific coping strategies (Buckelew et al.,1992; Williams \& Kinney, 1991) than chronic pain, and the effects of coping behaviors on health may actually vary according to whether a health problem - such as pain - is acute or chronic (Hall et al., 2010). The role of pain chronicity should therefore be addressed by future empirical studies.

Another issue for future research is the directionality of the associations investigated. As pointed out before, we assumed causal pathways leading from cognitive abilities, accommodative coping, and pain to functional health, but these associations might be more complex, including reversed or reciprocal pathways.

Also, we were unable to investigate the time-varying associations of coping strategies with functional health because accommodative coping was not assessed on every measurement occasion. However, coping strategies may be subject to change when individuals grow older (Brandtstädter \& Greve, 1994; Diehl et al., 2014) and when they are affected by chronic conditions (Wahl et al., 2005; Wettstein et al., 2019), which deserves additional investigation, particularly with regard to pain.

Finally, functional health was assessed based on selfreports. Although the SF-36 physical functioning subscale is an established and widely used assessment instrument with objectifiable items (such as walking one block), future research should additionally consider objective, performance-based functional health outcomes.

\section{Conclusion}

Older age and the experience of pain are associated with lower functional health, whereas higher informationprocessing speed is associated with better functional health and with a less steep functional health decline over 9 years. Going beyond such associations of singular risk and protective factors by considering "multi-indicator constellations" (Brandmaier et al., 2017), our findings suggest that information-processing speed and accommodative coping are important resources that play a compensatory role under high-vulnerability circumstances by buffering the negative associations of age and pain with functional health.

\section{References}

Arends, R. Y., Bode, C., Taal, E., \& Van de Laar, M. A. F. J. (2018). A goal management intervention for patients with polyarthritis and elevated levels of depressive symptoms: A quasiexperimental study. Disability and Rehabilitation, 1-10. https://doi. org/10.1080/09638288.2018.1513086

Atkinson, H. H., Rapp, S. R., Williamson, J. D., Lovato, J., Absher, J. R., Gass, M., ... Espeland, M. A. (2009). The relationship between cognitive function and physical performance in older women: Results from the Women's Health Initiative Memory Study. The Journals of Gerontology: Series A, 65A, 300-306. https://doi.org/10.1093/gerona/glp149

Bailly, N., Martinent, G., Ferrand, C., Gana, K., Joulain, M., \& Maintier, C. (2016). Tenacious goal pursuit and flexible goal adjustment in older people over 5 years: A latent profile transition analysis. Age and Ageing, 45, 287-292. https://doi. org/10.1093/ageing/afv203

Baltes, P. B. (1997). On the incomplete architecture of human ontogeny: Selection, optimization, and compensation as foundation of developmental theory. American Psychologist, 52, 366-380. https://doi.org/10.1037/0003-066x.52.4.366

Baltes, P. B., \& Smith, J. (2003). New frontiers in the future of aging: From successful aging of the young old to the dilemmas of the fourth age. Gerontology, 49, 123-135.

Berlau, D. J., Corrada, M. M., \& Kawas, C. (2009). The prevalence of disability in the oldest-old is high and continues to increase with age: Findings from The $90+$ Study. International Journal of Geriatric Psychiatry, 24, 1217-1225. https://doi.org/10.1002/ gps.2248

Boerner, K., \& Wang, S.-W. (2012). Targets for rehabilitation: An evidence base for adaptive coping with visual disability. Rehabilitation Psychology, 57, 320-327. https://doi.org/ 10.1037/a0030787

Brandmaier, A. M., Ram, N., Wagner, G. G., \& Gerstorf, D. (2017). Terminal decline in well-being: The role of multi-indicator constellations of physical health and psychosocial correlates. Developmental Psychology, 53, 996-1012. https://doi.org/ 10.1037/dev0000274

Brandtstädter, J. (2015). Adaptive resources of the aging self: Assimilative and accommodative modes of coping. In N. A. Pachana (Ed.), Encyclopedia of geropsychology (pp. 1-8). Singapore: Springer Singapore.

Brandtstädter, J., \& Greve, W. (1994). The aging self: Stabilizing and protective processes. Developmental Review, 14, 52-80. https://doi.org/10.1006/drev.1994.1003

Brandtstädter, J., \& Renner, G. (1990). Tenacious goal pursuit and flexible goal adjustment: Explication and age-related analysis of assimilative and accommodative strategies of coping. Psychology and Aging, 5, 58-67. https://doi.org/10.1037/0882-7974.5.1.58

Brandtstädter, J., \& Rothermund, K. (2002). The life-course dynamics of goal pursuit and goal adjustment: A two-process framework. Developmental Review, 22, 117-150. https://doi. org/10.1006/drev.2001.0539

Brandtstädter, J., Rothermund, K., Kranz, D., \& Kühn, W. (2010) Final decentrations. European Psychologist, 15, 152-163. https://doi.org/10.1027/1016-9040/a000019

Brennan-Ing, M., Boerner, K., Horowitz, A., \& Reinhardt, J. (2013). The vision-specific optimization in primary and secondary control (OPS) scale. European Journal of Ageing, 10, 345-352. https://doi.org/10.1007/s10433-013-0278-4

Bruckenthal, P., Reid, M. C., \& Reisner, L. (2009). Special issues in the management of chronic pain in older adults. Pain Medicine, 10(suppl 2), S67-S78. https://doi.org/10.1111/j.1526-4637.2009. 00667.x 
Bryant, L. L., Grigsby, J., Swenson, C., Scarbro, S., \& Baxter, J. (2007). Chronic pain increases the risk of decreasing physical performance in older adults: The San Luis Valley Health and Aging Study. The Journals of Gerontology: Series A, 62, 989-996. https://doi.org/10.1093/gerona/62.9.989

Buckelew, S. P., Conway, R. C., Shutty, M. S., Lawrence, J. A., Grafing, M. R., Anderson, S. K., ... Keefe, F. J. (1992). Spontaneous coping strategies to manage acute pain and anxiety during electrodiagnostic studies. Archives of Physical Medicine and Rehabilitation, 73, 594-598. https://doi.org/10.5555/uri: pii:0003999392901975

Bullinger, M., \& Kirchberger, I. (1998). SF-36. Fragebogen zum Gesundheitszustand [SF-36 Questionnaire Concerning Health Status. Manual]. Göttingen: Hogrefe.

Cook, A. J., \& Chastain, D. C. (2001). The classification of patients with chronic pain: Age and sex differences. Pain Research and Management, 6. https://doi.org/10.1155/2001/376352

Desjardins-Crépeau, L., Berryman, N., Vu, T. T. M., Villalpando, J. M., Kergoat, M.-J., Li, K. Z., ... Bherer, L. (2014). Physical functioning is associated with processing speed and executive functions in community-dwelling older adults. The Journals of Gerontology: Series B, 69, 837-844. https://doi.org/10.1093/ geronb/gbu036

Diehl, M., Chui, H., Hay, E. L., Lumley, M. A., Grühn, D., \& LabouvieVief, G. (2014). Change in coping and defense mechanisms across adulthood: Longitudinal findings in a European American sample. Developmental Psychology, 50, 634-648. https:// doi.org/10.1037/a0033619

Domenichiello, A. F., \& Ramsden, C. E. (2019). The silent epidemic of chronic pain in older adults. Progress in Neuro-Psychopharmacology and Biological Psychiatry, 93, 284-290. https://doi. org/10.1016/j.pnpbp.2019.04.006

Dupuy, L., N'Kaoua, B., Dehail, P., \& Sauzéon, H. (2019). Role of cognitive resources on everyday functioning among oldest-old physically frail. Aging Clinical and Experimental Research. https://doi.org/10.1007/s40520-019-01384-3

Eggermont, L. H. P., Leveille, S. G., Shi, L., Kiely, D. K., Shmerling, R. H., Jones, R. N., ... Bean, J. F. (2014). Pain characteristics associated with the onset of disability in older adults: The maintenance of balance, independent living, intellect, and zest in the Elderly Boston Study. Journal of the American Geriatrics Society, 62, 1007-1016. https://doi.org/10.1111/jgs.12848

Ehde, D. M., Dillworth, T. M., \& Turner, J. A. (2014). Cognitivebehavioral therapy for individuals with chronic pain: Efficacy, innovations, and directions for research. American Psychologist, 69, 153-166. https://doi.org/10.1037/a0035747

Finkel, D., Ernsth-Bravell, M., \& Pedersen, N. L. (2016). Temporal dynamics of motor functioning and cognitive aging. The Journals of Gerontology: Series A, 71, 109-116. https://doi.org/ 10.1093/gerona/glv110

Finkel, D., Reynolds, C. A., McArdle, J. J., \& Pedersen, N. L. (2007). Age changes in processing speed as a leading indicator of cognitive aging. Psychology and Aging, 22, 558-568. https://doi. org/10.1037/0882-7974.22.3.558

Freund, A. M., \& Baltes, P. B. (2002). Life-management strategies of selection, optimization and compensation: Measurement by self-report and construct validity. Journal of Personality and Social Psychology, 82, 642-662. https://doi.org/10.1037/00223514.82.4.642

Fuchs, J., Busch, M., Lange, C., \& Scheidt-Nave, C. (2012). Prevalence and patterns of morbidity among adults in Germany. Bundesgesundheitsblatt - Gesundheitsforschung Gesundheitsschutz, 55, 576-586. https://doi.org/10.1007/ s00103-012-1464-9

Hall, N. C., Chipperfield, J. G., Heckhausen, J., \& Perry, R. P. (2010). Control striving in older adults with serious health problems: A 9-year longitudinal study of survival, health, and well-being. Psychology and Aging, 25, 432-445. https://doi.org/ $10.1037 / a 0019278$

Haynes, T. L., Heckhausen, J., Chipperfield, J. G., Perry, R. P., \& Newall, N. E. (2009). Primary and secondary control strategies: Implications for health and well-being among older adults. Journal of Social and Clinical Psychology, 28, 165-197. https:// doi.org/10.1521/jscp.2009.28.2.165

Heikkinen, E. (2011). A life course approach: Research orientations and future challenges. European Review of Aging and Physical Activity, 8, 7-12. https://doi.org/10.1007/s11556-010-0069-2

Hellström, C., Jansson, B., \& Carlsson, S. G. (2000). Perceived future in chronic pain: The relationship between outlook on future and empirically derived psychological patient profiles. European Journal of Pain, 4, 283-290. https://doi.org/10.1053/ eujp.2000.0184

Heyl, V., \& Wahl, H.-W. (2012). Managing daily life with age-related sensory loss: Cognitive resources gain in importance. Psychology and Aging, 27, 510-521. https://doi.org/10.1037/a0025471

Heyl, V., Wahl, H.-W., \& Mollenkopf, H. (2007). Affective well-being in old age. European Psychologist, 12, 119-129. https://doi.org/ 10.1027/1016-9040.12.2.119

Hoffman, L., \& Stawski, R. S. (2009). Persons as contexts: Evaluating between-person and within-person effects in longitudinal analysis. Research in Human Development, 6(2/3), 97120. https://doi.org/10.1080/15427600902911189

Hox, J. J., \& Kreft, I. G. G. (1994). Multilevel analysis methods. Sociological Methods \& Research, 22, 283-299. https://doi.org/ 10.1177/0049124194022003001

Jacobs, J. M., Maaravi, Y., Cohen, A., Bursztyn, M., Ein-Mor, E., \& Stessman, J. (2012). Changing profile of health and function from age 70 to 85 years. Gerontology, 58, 313-321. https://doi. org/10.1159/000335238

Jakobsson, U., Klevsgård, R., Westergren, A., \& Hallberg, I. R. (2003). Old people in pain: A comparative study. Journal of Pain and Symptom Management, 26, 625-636. https://doi.org/ 10.1016/S0885-3924(03)00145-3

Jamison, R. N., \& Brown, G. K. (1991). Validation of hourly pain intensity profiles with chronic pain patients. pain, 45, 123-128. https://doi.org/10.1016/0304-3959(91)90176-X

Jamison, R. N., Rudy, T. E., Penzien, D. B., \& Mosley, T. H. (1994). Cognitive-behavioral classifications of chronic pain: Replication and extension of empirically derived patient profiles. pain, 57, 277-292. https://doi.org/10.1016/0304-3959(94)90003-5

Kashikar-Zuck, S., Sil, S., Lynch-Jordan, A. M., Ting, T. V., Peugh, J., Schikler, K. N., ... Lovell, D. J. (2013). Changes in pain coping, catastrophizing, and coping efficacy after cognitivebehavioral therapy in children and adolescents with juvenile fibromyalgia. The Journal of Pain, 14, 492-501. https://doi.org/ 10.1016/j.jpain.2012.12.019

Kass, R. E., \& Raftery, A. E. (1995). Bayes factors. Journal of the American Statistical Association, 90(430), 773-795. https://doi. org/10.1080/01621459.1995.10476572

Kelly, R. E., Wood, A. M., \& Mansell, W. (2013). Flexible and tenacious goal pursuit lead to improving well-being in an aging population: A ten-year cohort study. International Psychogeriatrics, 25, 16-24. https://doi.org/10.1017/S1041610212001391

Klaus, D., Engstler, H., Mahne, K., Wolff, J. K., Simonson, J., Wurm, S., \& Tesch-Römer, C. (2017). Cohort profile: The German Ageing Survey (DEAS). International Journal of Epidemiology, 46, 1105-1105g. https://doi.org/10.1093/ije/dyw326

Leigh, L., Byles, J. E., \& Mishra, G. D. (2017). Change in physical function among women as they age: Findings from the Australian Longitudinal Study on Women's Health. Quality of Life Research, 26, 981-991. https://doi.org/10.1007/s11136016-1422-3 
Leipold, B., \& Greve, W. (2009). Resilience - A conceptual bridge between coping and development. European Psychologist, 14, 40-50. https://doi.org/10.1027/1016-9040.14.1.40

Levy, B., Slade, M. D., \& Kasl, S. V. (2002). Longitudinal benefit of positive self-perceptions of aging on functional health. The Journals of Gerontology Series B: Psychological Sciences and Social Sciences, 57, 409-417. https://doi.org/10.1093/geronb/ 57.5.P409

Lindenberger, U., Mayr, U., \& Kliegl, R. (1993). Speed and intelligence in old age. Psychology and Aging, 8, 207-220. https://doi.org/10.1037/0882-7974.8.2.207

Loevinger, B. L., Shirtcliff, E. A., Muller, D., Alonso, C., \& Coe, C. L. (2012). Delineating psychological and biomedical profiles in a heterogeneous fibromyalgia population using cluster analysis. Clinical Rheumatology, 31, 677-685. https://doi.org/10.1007/ s10067-011-1912-1

Loidl, B., \& Leipold, B. (2019). Facets of accommodative coping in adulthood. Psychology and Aging, 34, 640-654. https://doi.org/ 10.1037/pag0000378

Molton, I. R., \& Terrill, A. L. (2014). Overview of persistent pain in older adults. American Psychologist, 69, 197-207. https://doi. org/10.1037/a0035794

Moor, C., Zimprich, D., Schmitt, M., \& Kliegel, M. (2006). Personality, aging self-perceptions, and subjective health: A mediation model. The International Journal of Aging and Human Development, 63, 241-257. https://doi.org/10.2190/AKRY-UM4K-PB1VPBHF

Praetorius Björk, M., Johansson, B., \& Hassing, L. B. (2016). I forgot when I lost my grip - Strong associations between cognition and grip strength in level of performance and change across time in relation to impending death. Neurobiology of Aging, 38, 68-72. https://doi.org/10.1016/j.neurobiolaging.2015.11.010

Ram, N., \& Grimm, K. J. (2015). Growth curve modeling and longitudinal factor analysis. In R. M. Lerner (Ed.), Handbook of child psychology and developmental science: Volume 1. Theory and method (7th ed., pp. 758-788). Hoboken, NJ: Wiley.

Rebok, G. W., Ball, K., Guey, L. T., Jones, R. N., Kim, H.-Y., King, J. W., ... Willis, S. L. (2014). Ten-year effects of the ACTIVE Cognitive Training Trial on cognition and everyday functioning in older adults. Journal of the American Geriatrics Society, 62, $16-$ 24. https://doi.org/10.1111/jgs.12607

Rothermund, K., \& Brandstädter, J. (2003). Coping with deficits and losses in later life: From compensatory action to accommodation. Psychology and Aging, 18, 896-905. https://doi.org/ 10.1037/0882-7974.18.4.896

Rowe, J. W., \& Kahn, R. L. (1997). Successful aging. The Gerontologist, 37, 433-440. https://doi.org/10.1093/geront/37.4.433

Royall, D. R., Palmer, R., Chiodo, L. K., \& Polk, M. J. (2004). Declining executive control in normal aging predicts change in functional status: The Freedom House Study. Journal of the American Geriatrics Society, 52, 346-352. https://doi.org/ 10.1111/j.1532-5415.2004.52104.x

Salthouse, T. A. (1996). The processing-speed theory of adult age differences in cognition. Psychological Review, 103, 403-428.

Sargent-Cox, K. A., Anstey, K. J., \& Luszcz, M. A. (2012). The relationship between change in self-perceptions of aging and physical functioning in older adults. Psychology and Aging, 27, 750-760. https://doi.org/10.1037/a0027578

Schepker, C. A., Leveille, S. G., Pedersen, M. M., Ward, R. E., Kurlinski, L. A., Grande, L., ... Bean, J. F. (2016). Effect of pain and mild cognitive impairment on mobility. Journal of the American Geriatrics Society, 64, 138-143. https://doi.org/ $10.1111 /$ jgs.13869

Schilling, O. K., Wahl, H.-W., \& Reidick, O. (2013). Trajectories of depressive symptoms in advanced old age: A functional approach concerning the role of physical functioning.
GeroPsych: The Journal of Gerontopsychology and Geriatric Psychiatry, 26, 29-38. https://doi.org/10.1024/1662-9647/ a000079

Schmiedek, F., Lövdén, M., \& Lindenberger, U. (2010). Hundred days of cognitive training enhance broad cognitive abilities in adulthood: Findings from the COGITO Study. Frontiers in Aging Neuroscience, 2, 27. https://doi.org/10.3389/fnagi.2010.00027

Schmitz, U., Saile, H., \& Nilges, P. (1996). Coping with chronic pain: Flexible goal adjustment as an interactive buffer against painrelated distress. pain, 67, 41-51. https://doi.org/10.1016/ 0304-3959(96)03108-9

Schöllgen, I., Morack, J., Infurna, F. J., Ram, N., \& Gerstorf, D. (2016). Health sensitivity: Age differences in the within-person coupling of individuals' physical health and well-being. Developmental Psychology, 52(11), 1944-1953. https://doi.org/ 10.1037/dev0000171

Schwartz, J. E., \& Stone, A. A. (1998). Strategies for analyzing ecological momentary assessment data. Health Psychology, 17, 6-16. https://doi.org/10.1037/0278-6133.17.1.6

Siltanen, S., Rantanen, T., Portegijs, E., Tourunen, A., PoranenClark, T., Eronen, J., \& Saajanaho, M. (2018). Association of tenacious goal pursuit and flexible goal adjustment with outof-home mobility among community-dwelling older people. Aging Clinical and Experimental Research, 31(9), 1249-1256. https://doi.org/10.1007/s40520-018-1074-y

StataCorp. (2017). Stata statistical software: Release 15. College Station, TX: StataCorp LLC.

Tewes, U. (1991). Hamburg-Wechsler-Intelligenztest für Erwachsene - Revision 1991 (HAWIE-R) [Wechsler Adult Intelligence Scale-Revision 1991 (WAIS-R)]. Bern: Hans Huber.

Turk, D. C., \& Rudy, T.E. (1988). Toward an empirically derived taxonomy of chronic pain patients: Integration of psychological assessment data. Journal of Consulting and Clinical Psychology, 56, 233-238. https://doi.org/10.1037/ 0022-006X.56.2.233

Turner, J. A., Holtzman, S., \& Mancl, L. (2007). Mediators, moderators, and predictors of therapeutic change in cognitive-behavioral therapy for chronic pain. pain, 127, 276-286. https://doi.org/10.1016/j.pain.2006.09.005

UNESCO. (2012). International standard classification of education ISCED 2011. Montreal: UNESCO Institute for Statistics.

van Diemen, T., van Nes, I. J. W., Geertzen, J. H. B., \& Post, M. W. M. (2018). Coping flexibility as predictor of distress in persons with spinal cord injury. Archives of Physical Medicine and Rehabilitation, 99, 2015-2021. https://doi.org/10.1016/j. apmr.2018.05.032

van Lankveld, W., van Diemen, T., \& van Nes, I. (2011). Coping with spinal cord injury: Tenacious goal pursuit and flexible goal adjustment. Journal of Rehabilitation Medicine, 43, 923-929.

Verbrugge, L. M., \& Jette, A. M. (1994). The disablement process. Social Science \& Medicine, 38, 1-14. https://doi.org/10.1016/ 0277-9536(94)90294-1

Wahl, H.-W., Becker, S., Schilling, O., Burmedi, D., \& Himmelsbach, I. (2005). Primäre und Sekundäre Kontrolle versus Hartnäckige Zielverfolgung und Flexible Zielanpassung: Das Beispiel Sehbeeinbeeinträchtigung im Alter [Primary and secondary control versus tenacious goal pursuit and flexible goal adjustment: The sample case of vision loss in old age]. Zeitschrift für Entwicklungspsychologie und Pädagogische Psychologie, 37, 57-68. https://doi.org/10.1026/0049-8637.37.2.57

Wahl, H.-W., Schmitt, M., Danner, D., \& Coppin, A. (2010). Is the emergence of functional ability decline in early old age related to change in speed of cognitive processing and also to change in personality? Journal of Aging and Health, 22, 691-712. https://doi.org/10.1177/0898264310372410 
Weiner, D. K., Rudy, T. E., Morrow, L., Slaboda, J., \& Lieber, S. (2006). The relationship between pain, neuropsychological performance, and physical function in community-dwelling older adults with chronic low back pain. Pain Medicine, 7 , 60-70. https://doi.org/10.1111/j.1526-4637.2006.00091.x

Wettstein, M., Eich, W., Bieber, C., \& Tesarz, J. (2019). Profiles of subjective well-being in patients with chronic back pain: Contrasting subjective and objective correlates. Pain Medicine, 20(4), 668-680. https://doi.org/10.1093/pm/pny162

Wettstein, M., Eich, W., Bieber, C., \& Tesarz, J. (2019). Pain intensity, disability, and quality of life in patients with chronic low back pain: Does age matter? Pain Medicine, 20, 464-475. https://doi.org/10.1093/pm/pny062

Wettstein, M., Schilling, O. K., \& Wahl, H. W. (2016). "Still feeling healthy after all these years": The paradox of subjective stability versus objective decline in very old adults' health and functioning across five years. Psychology and Aging, 31, 815-830.

Wettstein, M., \& Wahl, H.-W. (2017). Plasticity of aging. In N. A. Pachana (Ed.), Encyclopedia of geropsychology (pp. 1823-1831). Singapore: Springer Singapore.

Wettstein, M., Wahl, H. W., \& Heyl, V. (2019). Assimilative and accommodative coping in older adults with and without sensory impairment: Four-year change and prospective relations with affective well-being. Aging and Mental Health, 23(9), 1255-1262.

Williams, S. L., \& Kinney, P. J. (1991). Performance and nonperformance strategies for coping with acute pain: The role of perceived self-efficacy, expected outcomes, and attention. Cognitive Therapy and Research, 15, 1-19. https://doi.org/ 10.1007/bf01172939

Willis, S. L., Jay, G. M., Diehl, M., \& Marsiske, M. (1992). Longitudinal change and prediction of everyday task competence in the elderly. Research on Aging, 14, 68-91. https://doi.org/ $10.1177 / 0164027592141004$

World Health Organization. (2001). International classification of functioning, disability and health (ICF). Geneva, Switzerland: Author.

World Health Organization. (2015). 1st world report on ageing and health. Geneva, Switzerland: Author.

\section{History}

Received September 30, 2019

Accepted December 20, 2019

Published online March 11, 2020

\section{Conflict of Interest}

The authors declare no conflict of interest.

\section{Funding}

The German Ageing Survey was funded under Grant 301-1720-2/ 2 by the German Federal Ministry for Family, Senior Citizens, Women, and Youth. The content is the sole responsibility of the authors. This contribution is part of the project "Health Trajectories into Old Age - Ways into Need for Long-Term Care" that is funded by the National Association of Statutory Health Insurance Funds (GKV-Spitzenverband).

\section{Markus Wettstein}

German Centre of Gerontology

Manfred-von-Richthofen-Strasse 2

12101 Berlin

Germany

markus.wettstein@dza.de 